\title{
Efficiency of growing cotton with physiological active substance without application of mineral fertilizers in the case of Uzbekistan
}

\author{
Shukhrat Abdualimov ${ }^{1, *}$ and Dilobar Rakhimova ${ }^{1}$ \\ ${ }^{1}$ Tashkent State Agrarian University, University str., 2, Tashkent province, Uzbekistan, 100140
}

\begin{abstract}
Cotton growing is the main industry in Uzbekistan's agriculture, and the country has accumulated a great deal of scientific and practical experience in cotton growing. A number of scientific studies is being undertaken in this regard. Especially in the cotton industry of the republic in recent years, the widespread use of physiologically active substances in the cultivation of fairy tales, high and quality crops has achieved positive results. Physiologically active substances are added to the soil, or the seed is applied to the seed before planting and can be used during the cotton growing season. We believe that the physiologically active substances used have a natural basis and their safety can play a special role in the cultivation of organic cotton. This article explores the potential for seed germination, cotton growth and development, and the cultivation of future, high-quality, environmentally friendly cotton when Tevevit Boms physiologically active substance is applied at a rate of $300-1,000 \mathrm{~kg} / \mathrm{ha}$ during the preparation of the soil for planting without the use of chemical mineral fertilizers.
\end{abstract}

\section{Introduction}

Due to the fact that Uzbekistan ranks 5-6 among the largest cotton-growing countries in the world and cotton is grown on more than 1.0 million hectares, the cotton crop is exported to more than 30 countries in the form of fiber, yarn and other products and this is of economic importance of the country $[1,4]$.

Currently, the population of the country is growing, which leads to an increase in demand for agricultural products. At the same time, our irrigated lands are limited, and due to climate change, water scarcity, increasing salinity, unfavorable weather conditions, there are great difficulties in obtaining high quality crops $[2,7,8,11]$. It is known that in any soil and climatic conditions, the cultivation of early-maturing, high-yielding and high-quality cotton, resistant to external factors, resistant to diseases and pests, is a priority. In order to increase soil fertility and the efficiency of the use of macro and micro elements in the soil, to stimulate plant growth and development, the physiologically active substance Tevevit Boms is used [3]. The mechanism of action of Tevevit Boms is associated with the

\footnotetext{
*Corresponding author: abdualimov71@mail.ru
} 
improvement of metabolism in the plant and is accompanied by the activation of the activity of the photogorms auxin and cytokine, which regulate natural growth $[4,5]$.

Biostimulants play an important role in the care of plants, increasing their resistance to external influences as a result of global warming, environmental changes, sudden warming, low rainfall, drought, early spring or autumn, cool and cool weather [6, 7]. With the germination of seeds treated with physiologically active substances, plant growth and development are improved, resistance to drought, salinity, disease increases, natural soil fertility and efficiency of mineral fertilizers are increased, creating the basis for high and quality yields [9, 11]. Physiologically and biologically active substances are organic additives that affect the course of physiological processes in the plant. They are applied to plants as a working mixture, have a positive effect on vital processes and allow obtaining high and quality crops [10]. The effect of treatment with various stimulants on seeds and cotton during the growing season has been studied by many scientists on seedling germination and cotton growth [12].

Local scientists observed that the growth and development of 15 types of agricultural crops was accelerated, disease resistance and productivity increased when the biologically active substance chitosan was applied before sowing [10-14]. When cotton seeds of Aqdarya-5 variety were treated with stimulants $\mathrm{T}-86$, Nitrolin, Tj-85 and XS-2, field productivity increased and growth accelerated development, had a positive effect on leaf surface, cotton yield and fiber quality.

In such experiments $[13,14]$, when the seeds were treated with 'Mival' before sowing, they germinated smoothly and healthy, despite adverse weather conditions. 'Mival' allowed the sowing of hairless seeds in saline soils, accelerated flowering of cotton and increased fiber yield by $1-3 \%$.

Several researchers obtained positive results in the fight against fusarium wilt disease of cotton with pre-sowing seeds with Phytovac stimulator and during the growing season of cotton and it was noted that today in Bukhara region, fusarium wilt disease causes severe damage to cotton and Phytovak stimulator is highly effective in combating it $[2,3,5]$.

As the germination capacity and germination of seeds treated with carboxymethylchitosan increased, the seedlings grew healthier and the yield increased as a result of the development of barley. It was found that 'Bist' biopreparation was highly effective in increasing the resistance of cotton to wilt disease [4-7].

The intensity of photosynthesis can be increased by controlling the root feeding of the plant to grow high yields from crops. When microbiological preparations are applied to crops, substances secreted by the plant root provide carbohydrates, amino acids, organic acids and active enzymes for plant growth and development, providing amino acids, nucleic acids, vitamins and hormones, resulting in favorable conditions for the plant [9-11].

An analysis of the above literature shows that the use of growth regulators in cotton and other sectors of agriculture are expanding year by year, new types of stimulants are being extensively tested and recommendations are being made on the optimal timing and standards of application. However, no research has been conducted on the biological efficacy of the new Tevevit Boms medicine in cotton and no optimal standards and timing of its use have been developed, which is the basis for this research.

\section{Materials and methods}

The experiments were carried out in the field and in accordance with the manual "Methods of conducting field experiments" (T: 2007), developed at the Cotton Research Institute. The obtained data were analyzed mathematically by the method of B.A. Dospekhov [4]. 
The research was conducted in 2018-2020 in the conditions of typical gray soils of Tashkent province in the cotton variety "Andijan-37". The distance between the rows of cotton was $60 \mathrm{~cm}$. The experimental variants were $25 \mathrm{~m}$ long, $2.4 \mathrm{~m}$ wide, accounted for 60 $\mathrm{m}^{2}$ and placed in 3 reps. Experiment 3 years alfalfa and 1 year winter wheat were planted and mineral fertilizers were poured into the field after wheat was not applied. In the experiment, the seeds were sown in the same order in all variants, using $45 \mathrm{~kg}$ of seeds per hectare using a special seed drill.

Seed germination in each variant was calculated on the basis of all returns in the area of $10 \mathrm{~m}^{2}$ from the beginning of germination to the full germination of seeds. During the vegetation period of cotton, phenological observations were made in the first days of each month, including cotton height, number of harvested branches, number of true leaves, number of combs, flowers and buds, number of open buds in all variants in 25 plants in 3 turns in 75 plants. The cotton yield was determined by hand-picking of the ripened cotton in all plants in the designated area in the experimental options for all returns, measured on the scales, and converted to one hectare.

In the control variant, cotton was applied on the basis of generally accepted agrotechnical measures in accordance with conventional agrotechnology, and the annual rate of mineral fertilizers (NPK) was $200 \mathrm{~kg}$ per hectare of pure nitrogen, $140 \mathrm{~kg}$ of phosphorus and $100 \mathrm{~kg}$ of potassium, in variant 2 the rate of Boms was $600 \mathrm{~kg} / \mathrm{ha}$, and mineral fertilizers were applied at the rates of N-200, P-140, K-100 kg/ha. In options 3-5 of the experiment, Boms organic medicine 300 per hectare; Mineral fertilizers were not applied at all during the application period of cotton when applied at the norms of 600 and $1000 \mathrm{~kg}$. In the care of cotton in the experimental field, measures such as row spacing, irrigation, and weed control were generally performed in the same order in all variants.

Tevevit Boms is an organic fertilizer obtained by humification of brown coal and peat compost in dry, black, granular form. Contains humic and fulvoic acids, various macro and microelements. It converts phosphate and potassium, the most important elements in the soil, from an undigested form to an easily assimilated form. Restores soil fertility and increases the amount of humus, improves the microflora. Before sowing the seeds in the plowed field is poured into the soil and mixed to a depth of $8-10 \mathrm{~cm}$ into the ground. It is recommended to use in the morning and evening cool times. Safety level of IV class is considered as low toxicity.

\section{Results and discussion}

In the experiment with Biodux stimulant containing arachidonic acid $3.0 \mathrm{ml} /$ ton before sowing, $2.0 \mathrm{ml} / \mathrm{ha}$ during the flowering and flowering periods of cotton, germination of seedlings was $10.1-13.3 \%$ accelerated, accelerated plant growth and development, and achieved a yield of $4.7 \mathrm{q} /$ ha higher than the control, with a cotton yield of 44.0 quintals per hectare [3].

When the stimulator was applied to the seed at a rate of $2.2 \mathrm{~kg} / \mathrm{ton}$, germination of seedlings was accelerated, rapid growth and development of cotton was observed, the number of pods was increased by 1.0-2.0, cotton yield increased by $3-5 \mathrm{q} / \mathrm{ha}$ and yield rate increased [5].

Various biostimulants with an organic basis have had a positive effect on seedling germination, plant growth, development and increased productivity. Therefore, we conducted observations on the application of mineral fertilizers to cotton and its care in non-fertilized conditions to study the effect on the germination, growth, development and yield of seedlings when Boms organic preparation was applied to the soil before sowing seeds. Below we analyze the results from these studies. 
It is noted in the scientific literature that seed germination increases when treated with various physiologically active substances. In particular, in the Tashkent province, accelerated germination was observed during pre-sowing treatment of seeds with Nitrolin and Spark medicines. Similar data have been found in other experiments using different stimulants $[6,9,10]$.

In the experiment, the effect of Tevevit Boms on germination of seedlings when applied to the soil during the preparation of the soil for planting was studied. In the experimental variants, germination of seeds was observed in 6 periods, ie from May 10 to May 22. The initial observation revealed that on May 10, the control variant had 75.7 units per 10 square meters, while the Boms variant had 73.3-105.3 units. Then 12.05; 14.05; 17.05; On 20.05 and 22.05, in a similar situation, it was observed that the germination of seedlings at Boms $300-600 \mathrm{~kg} / \mathrm{ha}$ was higher than the control option.

In the last observation, on May 22, the number of seedlings germinated in the Boms $300-600 \mathrm{~kg} / \mathrm{ha}$ variants of the experiment was $231.7-234.0$, which was $4.4-6.7$ more than the 227.3 controls. However, the number of seedlings germinated in the variant applied to $1000 \mathrm{~kg}$ of Boms per hectare was 250.3, which was 23.0 more than the control. Hence, Boms had a positive effect on seedling germination when applied at 300-1000 kg per hectare (Table 1).

Table 1. Influence of Boms on seed germination, Andijan-37 variety of cotton, Tashkent 2019

\begin{tabular}{|c|c|c|c|c|c|c|c|c|c|}
\hline \multirow[b]{2}{*}{$\#$} & \multirow{2}{*}{ 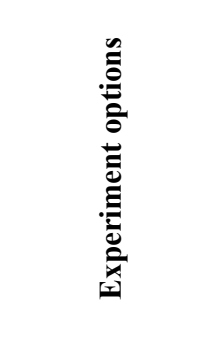 } & \multirow{2}{*}{ 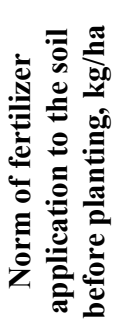 } & \multicolumn{6}{|c|}{ Number of sprouted seedlings per $10 \mathbf{m}^{2}$} & \multirow{2}{*}{ 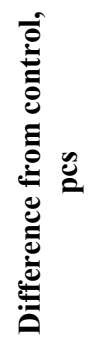 } \\
\hline & & & 10.05 & 12.05 & 14.05 & $\mathbf{1 7 . 0 5}$ & 20.05 & 22.05 & \\
\hline 1 & Control (NPK) & - & 75.7 & 161.0 & 174.0 & 196.0 & 216.0 & 227.3 & - \\
\hline 2 & Boms + NPK & 600 & 73.3 & 139.0 & 164.7 & 177.0 & 214.0 & 234.3 & 7.0 \\
\hline 3 & Boms & 300 & 105.3 & 144.3 & 185.0 & 203.3 & 225.0 & 231.7 & 4.4 \\
\hline 4 & Boms & 600 & 74.7 & 174.7 & 200.0 & 213.7 & 231.0 & 234.0 & 6.7 \\
\hline 5 & Boms & 1000 & 82.0 & 153.0 & 200.7 & 210.3 & 233.0 & 250.3 & 23.0 \\
\hline
\end{tabular}

Thus, in the period of preparation of the soil before sowing, Tevevit Boms was applied to the soil at the rate of $300-600-1000 \mathrm{~kg} / \mathrm{ha}$ found to have a positive effect on seedling germination.

In the experimental field, the effect of Boms medicine on plant growth and development during the growing season of cotton was studied (Table 2). In the observation conducted on June 1, 2019, there was no significant difference between the variants, with the length of the cotton being $9.2-10.8 \mathrm{~cm}$ according to the variants and the number of true leaves being 2.4-2.6.

In subsequent observations, during the period of mass weeding of cotton on July 1 in the control variant the plant height was $39.6 \mathrm{~cm}$, the number of harvested branches was 5.7 , the number of stalks was 5.7, Boms $600 \mathrm{~kg} / \mathrm{ha}+$ NPK and Boms 300-1000 kg/ha. 39.2-40.7 $\mathrm{cm}$, the number of fruiting branches is 5.5-6.0, the stems are 5.6-6.0, the length of the 
cotton is $0.9-1.1 \mathrm{~cm}$ lower than the control, the fruiting branches are $0.3-0.2$ pieces, and the combs were found to be $0.1-0.3$ pieces less.

Table 2. Influence of Boms on growth and development of cotton of Andijan-37 variety, Tashkent province, 2019

\begin{tabular}{|c|c|c|c|c|c|c|c|c|c|}
\hline \multirow[b]{2}{*}{ \# } & \multirow{2}{*}{ 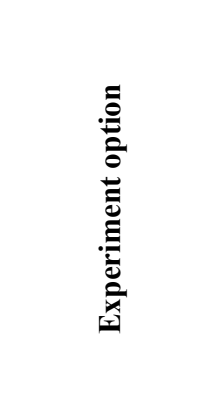 } & \multirow{2}{*}{ 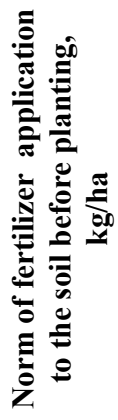 } & \multicolumn{2}{|c|}{$\begin{array}{l}\text { Height of } \\
\text { cotton, cm }\end{array}$} & \multicolumn{3}{|c|}{ Number of cocoons } & \multicolumn{2}{|c|}{$\begin{array}{l}\text { Mature } \\
\text { cocoons }\end{array}$} \\
\hline & & & 1.08 & 1.09 & 1.08 & 1.09 & 20.09 & Pes & $\%$ \\
\hline 1 & Control (NPK) & - & 83.7 & 94.4 & 5.6 & 8.8 & 9.3 & 5.7 & 61.3 \\
\hline 2 & Boms + NPK & 600 & 84.5 & 97.0 & 5.4 & 9.7 & 10.8 & 7.2 & 66.7 \\
\hline 3 & Boms & 300 & 82.7 & 91.6 & 5.2 & 9.9 & 10.5 & 7.2 & 68.6 \\
\hline 4 & Boms & 600 & 85.9 & 100.0 & 5.4 & 10.8 & 11.2 & 7.9 & 70.5 \\
\hline 5 & Boms & 1000 & 84.5 & 95.9 & 5.4 & 10.0 & 10.2 & 7.1 & 69.6 \\
\hline
\end{tabular}

Phenological observations during the flowering and fruiting periods of cotton (1.07 and 1.08.2019) also showed that in the variants used by Boms, the length of the cotton was lower and the number of harvested branches was less, but the number of combs, flowers and stalks was higher than the control. For example, at the end of the growing season (1.09.2019) the height of the cotton was $94.4 \mathrm{~cm}$ in the control, $97.0 \mathrm{~cm}$ in the Boms + NPK variant, $91.6 \mathrm{~cm}$ in the Boms $300 \mathrm{~kg} / \mathrm{ha}$ norm, $2.8 \mathrm{~cm}$ lower than the control, but 600 1000 in the Boms $\mathrm{kg} / \mathrm{ha}$ was $95.9-100.0 \mathrm{~cm}$ in the applied variants and $1.5-5.6 \mathrm{~cm}$ higher than the control. The number of harvested horns was 15.5 in the controls, while the number of horns in the controls was 15.0-16.0. The number of pods was 8.8 in the control variant, 9.7 in the variant given to Boms in the norm of $600 \mathrm{~kg} / \mathrm{ha}$ against the background of mineral fertilizers, 9.9-10.8 in the variant with cotton only in the norm of $300-1000 \mathrm{~kg} / \mathrm{ha}$ without mineral fertilizers or 1.1-2.0 units more than the control.

It should be noted that in the variants in which the medicine Boms was used, the vegetative mass was low due to the absence of mineral fertilizers during the care of cotton. This is explained by its short stature and low number of fruiting branches. However, by the time of cotton production and ripening, the number of generative organs increased in the Boms variant, and the number of pods in a control cotton field before September 20 was 9.3, compared to 10.8 in the Boms mineral fertilizer variant. 1.5 units more, when mineral fertilizers are not used at all and 10.5 units in the given option of Boms $300 \mathrm{~kg} / \mathrm{ha}, 11.2$ units in the norm of $600 \mathrm{~kg} / \mathrm{ha}$ of Boms, 10.2 units in the norm of $300-600 \mathrm{~kg}$ or 1000 $\mathrm{kg} / \mathrm{ha}$ of Boms, the number of cocoons was 0.9-1.9 more than the control. 
In the experiment, the maximum number of cocoons was observed in the Boms range of $300-600 \mathrm{~kg} / \mathrm{ha}$. It should be noted that in the experimental variants, the opening rate of the cocoons was 5.7 units or $61.3 \%$ in the control, while in the Boms-treated variants it was 7.1-7.9 units or 68.6-70.5\%, which is 7 times higher than in the control. , An acceleration of $3-9.2 \%$ was found.

Thus, the specific effect of Boms on the growth and development of cotton when applied to the soil was as follows: in the typical gray soils of Tashkent province, cotton is fed without mineral fertilizers (NPK) only when Boms is applied at a rate of $300-600 \mathrm{~kg} / \mathrm{ha}$. Although there was no significant difference in the number of cocoons, it was found that the number of cocoons collected was more than 0.9-1.9, and the opening of cocoons accelerated by $7.3-9.2 \%$.

Experiments have shown the effect of Boms on cotton yield. First of all, according to the options, the weight of cotton in one bale was $5.5 \mathrm{~g}$ in the control when measured, and 5.7-5.8 $\mathrm{g}$ in the treatment with Boms, which was 0.2-0.3 g heavier than the control. In the experimental variants, it was observed that the seedling thickness of cotton was 71.0-73.0 thousand bushes per hectare, close to each other (Table 3).

The yield of cotton grown in the experimental field in the first harvest was 28.1 in the control variant, 32.9 in the Boms + NPK variant, 33.3 in the Boms $300 \mathrm{~kg} / \mathrm{ha}, 34.8$ in the Boms $600 \mathrm{~kg} / \mathrm{ha}$ and 32.1 in the Boms $1000 \mathrm{~kg} / \mathrm{ha} . \mathrm{q} / \mathrm{ha}, 5.2-6.7 \mathrm{q} / \mathrm{ha}$ more cotton was harvested than the control of Boms $300-1000 \mathrm{~kg} / \mathrm{ha}$.

In the experimental variants, the yield was $6.8-8.3 \mathrm{q} /$ ha in the second harvest (Table 3 ).

Table 3. Effects on cotton yield when boms are used, Andijan-37 variety of cotton, 2019

\begin{tabular}{|c|c|c|c|c|c|c|c|c|c|}
\hline \multirow{3}{*}{ \# } & \multirow{3}{*}{ 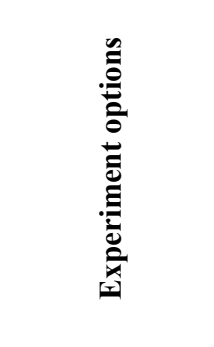 } & \multirow{3}{*}{ 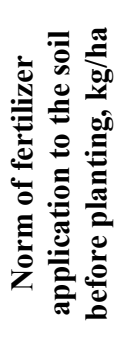 } & \multirow{3}{*}{ 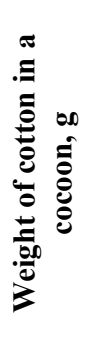 } & \multirow{3}{*}{ 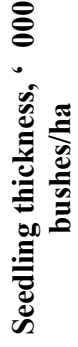 } & \multirow{2}{*}{\multicolumn{2}{|c|}{ 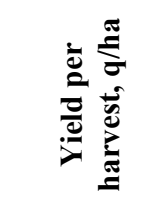 }} & \multirow{3}{*}{ 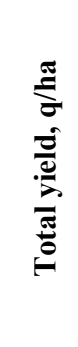 } & \multicolumn{2}{|c|}{ Additional yield } \\
\hline & & & & & & & & \multirow{2}{*}{ q/ha } & \multirow{2}{*}{$\%$} \\
\hline & & & & & 1 & 2 & & & \\
\hline 1 & Control (NPK) & - & 5.5 & 72.2 & 28.1 & 6.8 & 34.9 & - & - \\
\hline 2 & Boms+NPK & 600 & 5.8 & 71.0 & 32.9 & 8.3 & 41.2 & 6.3 & 18.1 \\
\hline 3 & Boms & 300 & 5.7 & 73.0 & 33.3 & 7.4 & 40.7 & 5.8 & 16.6 \\
\hline 4 & Boms & 600 & 5.7 & 72.4 & 34.8 & 7.0 & 41.8 & 6.9 & 19.8 \\
\hline 5 & Boms & 1000 & 5.7 & 71.0 & 32.1 & 8.0 & 40.1 & 5.2 & 14.9 \\
\hline
\end{tabular}

$H C P_{05}=2.2 q / h a, H_{C P}=5.1 \%$

Thus, in the typical pre-sowing preparation of soil in the conditions of typical gray soils of Tashkent province, when Boms biopreparation was used in the amount of 300-600 kg/ha, cotton yield was 40.7-41.8 t/ha, cotton yield increased by 5.8-6.9 t/ha and 16.6-19.8\% high yield was obtained.

\section{Conclusion}

In the conditions of typical gray soils of Tashkent province, the use of Tevevit Boms at a rate of $300-600 \mathrm{~kg} / \mathrm{ha}$ during the preparation of the soil for planting is an effective method 
for the cultivation of early, high-quality cotton without the use of mineral fertilizers (NPK) in cotton, as well as organic organic products. The use of physiologically active substances has been scientifically and practically proven to give high results.

\section{References}

1. N. Teshaev, B. Mamataliyev, A. Ibragimov, S. Khasanov, InterCarto. InterGIS 26(3), 324-333 (2020)

2. SH. Abdualimov, F. Khasanova, SH. Karimov, Uzbek Journal of Agriculture 4, 2-3 (2017)

3. SH. Abdualimov, SH. Karimov, Actual problems of modern science 4, 262-266 (2017)

4. S. Isaev, I. Begmatov, G. Goziev, S. Khasanov, IOP Publishing 883(1), 012080 (2020)

5. Methods of conducting field experiments, 147 (UzPITI Press, Tashkent, 2007)

6. B. A. Dospekhov, Field experiment technique 7, 248-256 (2015)

7. S. K. Isaev, R. U. Rakhmonov, S. S. Tadjiev, G. I. Goziev, S. Z. Khasanov, IOP Publishing 614(1), 012147 (2020)

8. R. A. Kulmatov, S. A. Adilov, S. Khasanov, IOP Publishing 614(1), 012149 (2020)

9. K. Mirzajanov, R. Rakhmonov, Uzbek Journal of Agriculture, 23-26 (2018)

10. R. Nazarov, Agro-knowledge 1(39), 6-7 (2016)

11. A. Jumanov, S. Khasanov, A. Tabayev, G. Goziev, U. Uzbekov, E. Malikov, IOP Publishing 614(1), 012150 (2020)

12. B. Umarov, M. Sattarov, A. Abdullaev, Agro-knowledge 1(39), 68-69 (2016)

13. D. Khudayberdieva, Agro-knowledge 2(30), 12-13 (2014)

14. A. Khan, D. K. Y. Tan, F. Munsif, M. Z. Afridi, F. Shah, F. Wei, R. Zhou, Environmental Science and Pollution Research 24(30), 23471-23487 (2017) 